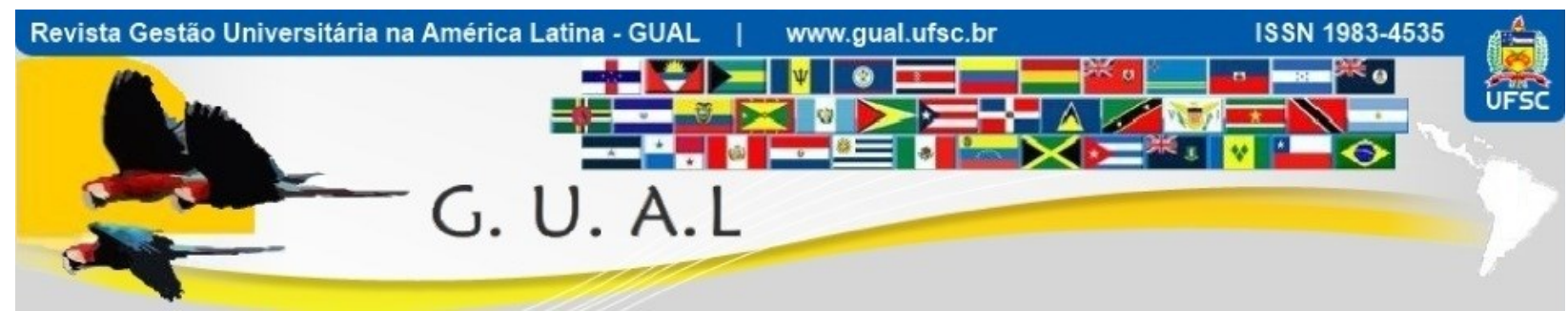

DOI: http://dx.doi.org/10.5007/1983-4535.2016v9n3p67

\title{
ANÁLISE COMPARATIVA DE CINCO UNIVERSIDADES FEDERAIS BRASILEIRAS: RELAÇÕES ENTRE ORÇAMENTOS, SERVIDORES E DISCENTES
}

\section{COMPARATIVE ANALYSIS OF FIVE BRAZILIAN FEDERAL UNIVERSITIES: RELATION BETWEEN BUDGETS, PUBLIC SERVANTS AND STUDENTS}

Julio Eduardo Ornelas Silva, Doutorando Universidade Federal de Santa Catarina - UFSC julioornelas@yahoo.com.br

Vitor Augusto da Rocha Mendes, Graduando Universidade Federal de Santa Catarina - UFSC vitorrarm@,gmail.com

Maristela Helena Zimmer Bortolini, Mestre Universidade Federal de Santa Catarina - UFSC maristela.bortolini@ufsc.br

Gabriela Tavares da Silva, Graduanda Universidade Federal de Santa Catarina - UFSC gabriela.tds@hotmail.com

Marília Ribas Machado, Mestranda Universidade Federal de Santa Catarina - UFSC marilia.ribas9@gmail.com

Michelle Bianchini de Melo, Doutorando Universidade Federal de Santa Catarina - UFSC chelymelo@gmail.com

Recebido em 15/abril/2015

Aprovado em 21/julho/2016

Sistema de Avaliação: Double Blind Review 


\title{
RESUMO
}

O objetivo da pesquisa foi apontar a possível relação entre quantitativo de servidores, discentes e orçamentos das universidades federais brasileiras, por meio da análise documental dos Relatórios de Gestão das instituições, da Lei Orçamentária Anual e dos Planos de Desenvolvimento Institucional. Foram selecionadas uma universidade por região brasileira, considerando a de maior orçamento. Apesar da utilização de dados quantitativos, a pesquisa classifica-se como qualitativa, pois não teve o propósito de realizar cálculos estatísticos, mas sim de análises interpretativas com o suporte de dados numéricos. Os resultados indicam que não há relação direta entre quantitativo de servidores, discentes e orçamentos das universidades federais brasileiras, uma vez que dentre todas as instituições analisadas, uma instituição apresenta dados claramente fora do padrão. Apenas duas variáveis, quantitativo de estudantes e orçamento das instituições possuem relação quando analisadas de forma isolada. Observou-se também que o orçamento de pessoal é o item de maior destinação nos orçamentos, tendo em vista serem as pessoas os agentes principais na educação superior, estruturando as intuições a possuírem um órgão de staff para a gestão de pessoas.

Palavras-chave: Universidades. Planejamento. Orçamento.

\begin{abstract}
The main objective of this study was to point relation between quantitative of public servants, students and budget of Brazilian federal universities, through document analysis of management reports of Annual Budget Law and Plan of Institutional Development. Were select one university of each Brazilian region considering at the biggest budget. Although of use of quantitative data, this study was classified as qualitative, because does not have a propose to realize statistical calculations, but interpretative analysis with support of numerical data. The results shows there was not direct relation between quantitative of public servants, students and budget of Brazilian federal universities, because all the universities that was analysed, only one demonstrated nonstandard datas. Only two varieties, quantitative of students and budget of Brazilian universities have relation if separately analysed. It is noted of personnel budget is the most large representation on budgets, bearing in mind the people are the main agent on the higher education, structuring the universities to have an organ relevant for the management people.
\end{abstract}

Key words:Universities. Planning. Budget. 


\section{INTRODUÇÃO}

A importância das universidades vem sendo objeto de estudos de muitas publicações acadêmicas ao redor do mundo, em virtude da sua capacidade de gerar e transmitir conhecimentos por gerações, fomentando o desenvolvimento social, econômico, cultural, tecnológico e científico no ambiente em que está inserida. Desde os primórdios da idade média que as universidades concentram o saber e estimulam o desenvolvimento da sociedade que a circunda, tendo uma ação mais significativa a partir da primeira Revolução Industrial.

É consolidado na literatura das ciências administrativas que as pessoas são o fator chave das organizações, a força motriz sem a qual não haveria razão de existir, pois por mais recursos que haja, sempre será preciso de colaboradores para estimular a produção e consumidores para o consumo. Assim, estudos para entender e motivar pessoas surgiram demasiadamente, especialmente a partir da Escola de Relações Humanas.

Conciliando os dois assuntos, verifica-se que universidades, enquanto organizações, também dependem de pessoas para a realização de suas atividades. E tendo em vista a geração e transmissão de conhecimentos, é preciso ter professores e alunos que exerçam esse processo, bem como profissionais que deem o suporte necessário para a atuação daqueles. Percebe-se assim que as pessoas são a razão de sucesso de uma universidade, e sua produção acadêmica refletirá a qualidade institucional.

Foi com base nesse contexto que os autores almejaram conhecer melhor a realidade de pessoal das universidades federais brasileiras, definindo como objetivo analisar a possível relação entre quantitativo de servidores, discentes e orçamentos das universidades federais brasileiras. Espera-se com esse estudo inicial, que seja possível definir um panorama preliminar para outros estudos qualitativos que compreendam a relação entre servidores e alunos, e a importância dos mesmos para a instituição, expresso por meio de seus orçamentos.

Considerando o orçamento uma parte importante para qualquer organização, por estar expresso as despesas consideradas significativas e necessárias para o seu exercício, o presente artigo abordou tanto o tema gestão de pessoas quanto o tema planejamento, considerando que uma parte do orçamento pode ser explicado por meio do processo de planejamento. No entanto, analisou-se o planejamento não somente pela visão orçamentária como também pela visão maior da instituição, o planejamento institucional que para as universidades federais, se expressa no documento denominado de Plano de Desenvolvimento Institucional - PDI. Dessa 
forma, o PDI e os orçamentos são os documentos essenciais para a consecução da pesquisa do presente artigo.

\section{FUNDAMENTOS TEÓRICOS}

\subsection{PLANEJAMENTO}

Henry Fayol se destacou na escola do processo de administração por ser um integrante ativo que sintetizou e difundiu os princípios da escola clássica. Em seu livro Administração geral e industrial, publicado em 1916, Fayol distingue a função administrativa das demais funções da empresa, e lhe configurou, conforme Maximiano (2011, p.72), como "uma atividade comum a todos os empreendimentos humanos (família, negócios, governo) que sempre exigem algum grau de planejamento, organização, comando, coordenação e controle". A figura 1 ilustra as funções da empresa e de administração propostas por Fayol.

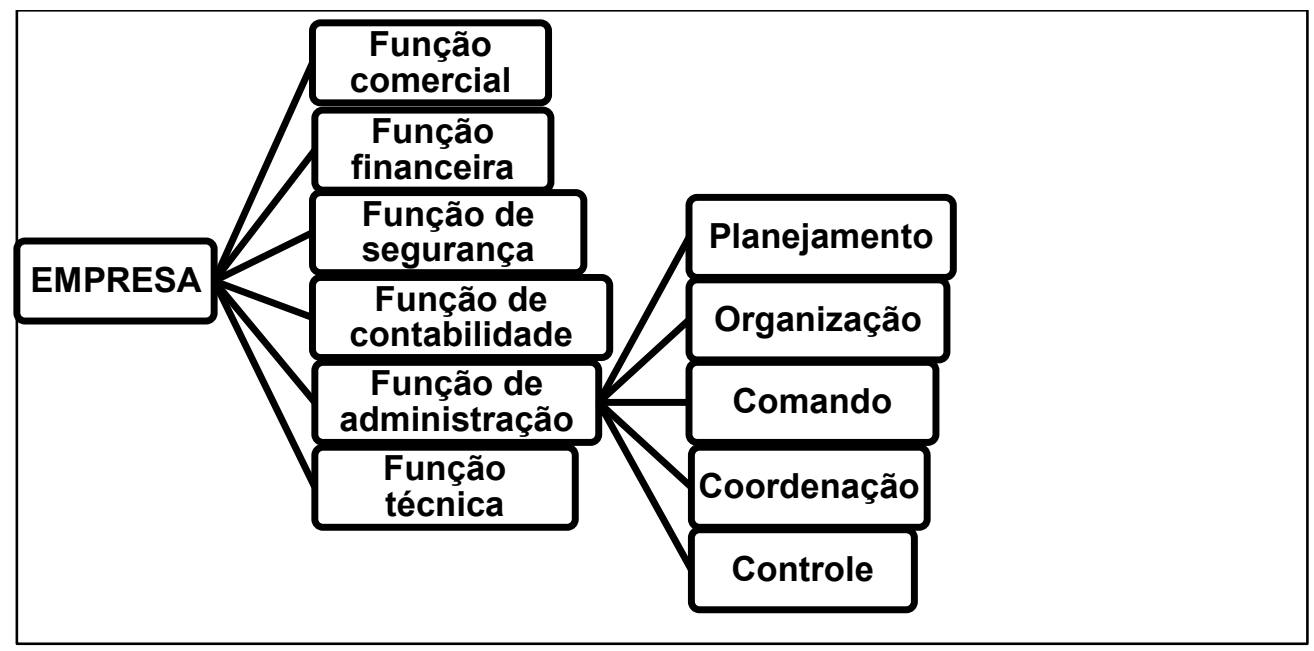

Figura 1 Funções da empresa.

Fonte: Adaptado de Maximiano (2011, p. 72).

No entendimento de Fayol, a função administrativa é a mais importante no ambiente da organização (MAXIMIANO, 2011), sendo dado maior atenção neste artigo, à função planejamento.

$\mathrm{O}$ processo de planejamento abrange um leque de procedimentos que pode ser explicado de várias maneiras, tais como os propostos por Maximiano (2000):

- definir objetivos a serem alcançados a médio e longo prazo;

- organizar técnicas para alcançar as metas da organização, tomando decisões quanto escolha dos recursos; 


\section{ANÁLISE COMPARATIVA DE CINCO UNIVERSIDADES FEDERAIS BRASILEIRAS: RELAÇÕES \\ ENTRE ORÇAMENTOS, SERVIDORES E DISCENTES \\ DOI: http://dx.doi.org/10.5007/1983-4535.2016v9n3p67}

- interferir na realidade para transpor a uma situação desejada;

- adotar providências para diminuir a incerteza quanto ao futuro.

Algumas situações sob controle da organização podem ser previstas com um maior grau de precisão, mas as flutuações no ambiente externo o tornam mais complexo, requerendo uma dinamicidade para o equilíbrio entre os subsistemas internos e o sistema total. Com o passar do tempo e a mudança da conjuntura, faz com que o objetivo precise ser alterado, ou os meios para a sua aplicação ajustados. (MAXIMIANO, 2000)

A permanência das organizações deriva da capacidade dos gestores de administrarem seus recursos internos e as relações com o ambiente. Maximiano (2000, p. 178) descreve a atitude como sendo proativa ou reativa, sendo ambas complementares e necessárias. "A atitude proativa é importante para o crescimento e a mudança; a atitude reativa é importante para manter o equilíbrio e impedir mudanças abruptas e desnecessárias”.

\begin{tabular}{|l|l|}
\hline \multicolumn{1}{|c|}{ PROATIVA } & \multicolumn{1}{c|}{ REATIVA } \\
\hline - forças que impulsionam e desejam a mudança; & - forças que desejam e preservam a estabilidade; \\
- espírito renovador; & - apego às tradições; \\
- capacidade de adaptação a novas situações; & - espírito conservador; \\
- antecipação de novas situações. & - incapacidade de adaptação a novas situações. \\
\hline
\end{tabular}

Quadro 1 Forças proativas e reativas.

Fonte: Adaptado Maximiano (2000, p. 177).

Na concepção de Oliveira (2008), podem-se distinguir três tipos de planejamento, sendo o estratégico, o tático e o operacional, no qual cada um compreende o nível hierárquico das decisões organizacionais. O planejamento operacional é a normatização da sistemática de desenvolvimento, visando as atividades rotineiras da instituição. No que se refere ao planejamento tático, o objetivo é de aperfeiçoar os níveis organizacionais intermediários para uma maior eficiência no manuseio dos recursos.

Diferente do planejamento tático, que potencializa determinada área de resultado, o planejamento estratégico, para Oliveira (2008), opera a organização como um todo, sendo um processo autêntico e dinâmico para integrar as funções da organização com o ambiente externo, estabelecendo uma metodologia que oriente o progresso da organização. 


\subsubsection{Plano de Desenvolvimento Institucional}

O Plano de Desenvolvimento Institucional - PDI foi instituído pelo Decreto $\mathrm{n}^{\mathrm{o}} 3.860$, de 9 de julho de 2001, em que cada instituição de ensino superior, pública ou privada, defina sua estrutura institucional, missão, objetivos e estratégias de conduta, tanto no setor acadêmico como administrativo (MURIEL, 2006).

Embora a elaboração do PDI seja relativamente recente, ao longo dos anos a legislação sobre o documento vem se adequando a um setor em expansão concorrencial (MURIEL, 2006). A concepção do plano está fundamentada na Lei de Diretrizes e Bases da Educação Nacional, e para a sua orientação e formulação, toma-se como base alguns dispositivos legais que a procederam (BRASIL, 2007):

Lei $\mathrm{N}^{\circ}$ 9.394/1996 (LDB), Decreto n. 5.773/2006, Lei $\mathrm{N}^{\circ} 10.861 / 2004$, Decreto $\mathrm{N}^{\circ}$ 2.494/1998, Decreto No 5.224/2004; Portaria MEC No 1.466/2001, Portaria MEC No 2.253/2001, Portaria MEC No 3.284/2003, Portaria MEC No 7/2004, Portaria MEC $\mathrm{N}^{\mathrm{o}}$ 2.051/2004, Portaria MEC $\mathrm{n}^{\mathrm{o}}$ 4.361/2004, Portarias Normativas n.1/2007, Portaria Normativa n, 2/2007, Resolução CES/CNE No 2/1998, Resolução CNE/CP No 1/1999, Resolução CES/CNE No 1/2001, Resolução CP/CNE No 1/2002 (art. $7^{\circ}$ ), Parecer CES/CNE No 1.070/1999.

A recomendação do Ministério da Educação para a elaboração do PDI é de que se considerem alguns princípios, como clareza, objetividade, coerência e factibilidade (BRASIL, 2004b). Ainda que o documento possa ser feito de maneira autônoma e livre, há algumas exigências que devem ser seguidas, dispostas no art. 16 do Decreto $\mathrm{n}^{\circ} 5.773$ :

i) Missão e metas da instituição;

ii) Projeto pedagógico, cronograma de implantação e desenvolvimento dos cursos;

iii) Organização didático-pedagógica;

iv) Perfil do corpo docente;

v)Organização da gestão administrativa;

vi) Infraestrutura física e instalações acadêmicas;

vii) Oferta de educação a distancia;

viii) Oferta de pós-graduação;

ix) Demonstrativo de capacidade e sustentabilidade financeira.

A resolução n ${ }^{\circ} 10$ do Conselho Nacional da Educação, de 11 de março de 2002 (CNE, 2002), evidencia que o PDI é imprescindível para o credenciamento e recredenciamento da instituição de educação superior - IES perante o MEC, devendo ser elaborado para um período de vigência de cinco anos. Com base no parecer n ${ }^{\circ} 310$ de 1999, o PDI serve não apenas como um orientador para a gestão universitária, mas um indicador para avaliação e fiscalização do MEC (MURIEL, 2006). Neste sentido, a Lei Federal $n^{\circ}$ 10.861, de 2004, 
estabeleceu o Sistema Nacional de Avaliação da Educação Superior - SINAES (BRASIL, 2004a), visando garantir a atividade das IES, dos cursos e o desempenho acadêmico dos discentes, tendo como intuito a melhoria na capacidade das instituições no que diz respeito a área acadêmica e social.

Por meio da Portaria $n^{\circ}$ 637, o MEC determina os critérios para a implantação do PDI nas IES, que segundo Muriel (2006, p. 63) seguem um padrão, demonstrando sua peculiaridade "apenas pela forma de organização acadêmica e pela competência e criatividade dos profissionais que cuidam do planejamento em cada instituição". Conforme citação de Francisco (2012, p. 84) em um artigo, “o PDI passa a se consolidar como um documento dinâmico e sistêmico no cerne institucional, já que passa a sofrer influência de indicadores que devem constituir a identidade e a orientação qualitativa da instituição".

Muriel (2006, p.68) destaca também que, além do PDI ser um compromisso da instituição para com o Ministério da Educação, é "um documento norteador e essencial para o seu desenvolvimento", contribuindo para o planejamento estratégico e gestão das IES.

\subsection{GESTÃO DE PESSOAS}

A área de gestão de pessoas visa gerir as relações intrainstitucionais das pessoas que atuam em uma organização, focada continuamente, na percepção de Ribeiro (2006, p. 06) a "alcançar seus objetivos e realizar suas missões". Considerando a individualidade de cada agente e os valores da entidade, faz-se necessário harmonizar a convivência, para que os membros não sejam meros colegas, mas se considerem o que o autor denomina de parceiros do negócio.

Mas as relações humanas nem sempre tiveram esse ponto de vista. Até meados da década de 1920, a relação gestor-empregado tinha como base uma abordagem mecânica, visando satisfazer exclusivamente os objetivos da organização, em que o empregado, considerado um recurso, poderia ser substituído para diminuir os custos e aumentar a produtividade. Com a promulgação de leis trabalhistas que instauraram benefícios trabalhistas, como a previdência social e a carga horária, se fortaleceu os sindicatos e trouxe uma nova perspectiva para o vínculo empregatício. Houve o reconhecimento da importância do trabalhador como membro da organização, consolidando uma abordagem mais social e humana (FLIPPO, 1978). 


\section{ANÁLISE COMPARATIVA DE CINCO UNIVERSIDADES FEDERAIS BRASILEIRAS: RELAÇÕES \\ ENTRE ORÇAMENTOS, SERVIDORES E DISCENTES \\ DOI: http://dx.doi.org/10.5007/1983-4535.2016v9n3p67}

Nos primórdios do século XX, a partir da regulação da legislação trabalhista, o que era denominado de chefe de pessoal, encarregado por manter a função produtiva do trabalhador, converteu-se em departamento de pessoas, dando-se maior importância nas questões rotineiras à administração organizacional, limitando o profissional a auxiliar a administração a proceder de forma legal às burocracias trabalhistas (ARAUJO; GARCIA, 2009).

Entre as décadas de 1950 e 1970 uma série de desenvolvimentos tecnológicos transformou o modelo de estrutura produtiva, motivando estudos significativos na literatura sobre Recursos Humanos. Um dos precursores da conceituação é Flippo (1978), que define a administração de pessoal com duas funções, a administrativa e a operativa. A função operativa é adotada pela pessoa que não tem autoridade sobre outra, e apenas exerce uma tarefa que lhe foi delegada, tendo entre as atividades a seleção, o desenvolvimento, a remuneração, a integração e a manutenção do pessoal. Assim, Flippo (1978, p. 25) indica que a "administração pessoal é planejar, organizar, dirigir e controlar o desempenho daquelas funções operativas".

Outra linha de classificação foi elaborada por Lobos (1979), que aborda um enfoque sistêmico na administração de recursos humanos. Esse enfoque percebe a organização como um conjunto de subsistemas composto por pessoas com experiências, desejos e esperança e um modelo tecnológico programado que necessita de manejo. Nesse caso, o principal objetivo do sistema de administração de recursos humanos é manter em sincronia as forças sociais e tecnológicas, garantindo máxima eficiência e eficácia, com suas atividades guiadas pelas funções básicas de planejamento, execução e controle.

Aquino (1980) admite a concepção de Lobos (1979), ao analisar a organização como um sistema que necessita de uma política integrativa entre os agentes produtivos, visando gerar uma relação sólida e duradoura entre empregador e empregado, otimizando o rendimento. A coordenação da área de recursos humanos deve ser previamente definida por meio do planejamento estratégico, formulado a partir da estrutura da organização e seus objetivos. De acordo com o autor, as funções da administração de recursos humanos são cinco: procura, desenvolvimento, manutenção, pesquisa e utilização.

Uma medida imprescindível para a ordem do sistema integrado é o estabelecimento de diretrizes, que nortearão todas as decisões de nível administrativo. Como se refere Aquino (1980, p. 117), as diretrizes de recursos humanos "são orientações gerais de longo prazo, brotados da realidade, da cultura, dos valores, e da base institucional da empresa". 
Dutra (1996) por sua vez, entende que a cultura organizacional gera identidade e coerência para o cotidiano, sendo previamente planejada pela gestão de recursos humanos para que suas políticas e práticas se adequem às condições do ambiente externo. O processo de mudança da cultura organizacional deve buscar incessantemente aprendizagem, flexibilidade e inovação (FRANZONI; LAPOLLI, 2009). O êxito do novo paradigma está intrinsecamente conectado ao talento e competências pessoais, que vêm sendo o diferencial para um ambiente cada vez mais competitivo e incerto (DUTRA, 1996).

A estratégia da organização e a gestão de pessoas influenciam-se mutuamente, pois as competências pessoais que são premissas para a formulação do planejamento, são as mesmas que executam a estratégia. Conforme definição de Dutra (2002, p.67-68), a gestão estratégica de pessoas é "um processo estruturado de interação das pessoas, [...] de forma a construir um projeto coletivo de desenvolvimento". As relações entre organização e pessoas tem se tornado mais dinâmicas, e para que haja conciliação das expectativas ambas as partes devem se estimular a um incessante ciclo de aprendizagem e adaptabilidade.

Atualmente, o departamento de recursos humanos abrange um leque de responsabilidades, que envolvem basicamente os empregados, variando suas funções desde o processo seletivo até o desvínculo empregatício. Em meio a esse processo os gestores devem optar por uma atuação estratégica, adotando ações que aperfeiçoem a capacidade individual e gerem um ambiente de trabalho oportuno a novas ideias (RIBEIRO, 2006). O quadro a seguir aponta os papéis antigo e atual da área de recursos humanos.

\section{O VELHO PAPEL DE RH}

-Controlar rigidamente a carreira dos funcionários;

-Manter a escala salarial em segredo;

-Manter a avaliação de potencial como tarefa exclusiva de RH;

-Entender que a manutenção de um clima organizacional é exclusiva do RH;

-Conservar a imagem do RH como um departamento a parte da organização e cheio de mistérios;

-Valorizar excessivamente a área, supondo que as atividades de linha de frente não têm chance de operar sem o RH;

-Oferecer treinamento de maneira não muito clara;

-Fazer com que os custos de pessoal não digam respeito a área de $\mathrm{RH}$, e sim a cada setor, respectivamente.

\section{O NOVO PAPEL DE RH}

-Propor, definir e garantir um conjunto de normas e procedimentos alinhados com os princípios institucionais e de acordo com a Legislação Trabalhista;

-Criar e operar sistemas em que as oportunidades de carreira estejam disponíveis a todos;

-Dar suporte as demais unidades da empresa prestadora de serviços ou funcionar como facilitador nos processos de administração de pessoas;

-Criar, propor e administrar instrumentos que possibilitem uma remuneração competitiva;

-Buscar sempre a diversidade, com objetivo de aumentar o capital intelectual, de modo a garantir a 
capacidade de inovação e atualização da empresa;

-Ter o treinamento como a principal ferramenta para a retenção do capital humano, e desenvolver novas competências;

-Dignificar o trabalho e o ser humano.

Quadro 2 Papéis antigo e novo da área de recursos humanos.

Fonte: Adaptado Ribeiro (2006, p. 16-17).

\section{METODOLOGIA}

A pesquisa pode ser caracterizada como estudo de múltiplos casos, pois foi estuda uma instituição de cada região brasileira. Para Cruz e Ribeiro (2003), o estudo de caso pretende estudar determinadas instituições, buscando obter generalizações, sendo para Gil (2010) uma análise profunda e exaustiva de poucos objetos de estudos, possibilitando um conhecimento mais amplo e detalhado do mesmo.

A seleção das instituições deu-se em virtude da análise de seus orçamentos totais do ano de 2014, apresentados na Lei Orçamentária Anual de 2015, que possuía os dados consolidados do ano anterior. Dessa forma, classificou-se os orçamentos por ordem crescente, e selecionou-se a instituição com maior orçamento em sua região. Dessa forma, foram selecionadas:

- Região Norte: Universidade Federal do Pará - UFPA;

- Região Nordeste: Universidade Federal do Rio Grande do Norte - UFRGN;

- Região Centro-Oeste: Universidade de Brasília - UnB;

- Região Sudeste: Universidade Federal do Rio de Janeiro - UFRJ;

- Região Sul: Universidade Federal do Rio Grande do Sul - UFRGS.

Os pesquisadores buscaram utilizar dados recentes, do ano de 2015, no entanto, tendo em vista que alguns relatório de gestão de 2015 não estavam disponíveis até a coleta dos dados, e buscando uniformar o período de análise, optou-se pelo ano de 2014.

Selecionadas as instituições, os pesquisadores buscaram documentos que apresentassem as informações necessárias para responder ao objetivo do artigo. Dessa forma, a pesquisa caracteriza-se como pesquisa documental, em consonância com o entendimento de Mattar (2008), de que informações importantes e ricas podem ser encontradas em documentos institucionais. Os pesquisadores utilizaram como referência os Relatórios de Gestão das instituições, que por força de legislação devem ser enviadas ao Tribunal de Contas da União para apreciação, e após, são disponibilizadas publicamente pelo próprio Tribunal.

Assim, foi possível analisar cinco relatórios de gestão cujas informações estavam dispostas com alguma padronização em suas seções. Além dos relatórios, dados 
orçamentários foram coletados da Lei Orçamentária Anual de 2015, com dados de 2014, bem como os Planos de Desenvolvimento Institucionais vigentes.

Coletados os dados, os mesmos foram consolidados e são apresentados na seção de resultados, na forma textual, com tabelas ou gráfico, possibilitando assim proceder análises interpretativistas. Apesar da utilização de dados quantitativos, a pesquisa é classificada como qualitativa, pois não teve como objetivo realizar cálculos estatísticos de dados numéricos para se chegar a conclusões, mas sim análises interpretativas de dados textuais e numéricos.

Apesar da importância e grandeza da Universidade Federal do Rio de Janeiro e da Universidade Federal do Rio Grande do Sul, a pesquisa não encontrou de forma pública, seus Planos de Desenvolvimento Institucional vigentes, sendo uma das limitações da pesquisa.

\section{RESULTADOS}

O levantamento dos orçamentos de todas as universidades federais para o ano de 2014 possibilitou filtrar as cinco instituições com maior volume de recursos orçamentários por região brasileira, sendo a Universidade Federal do Pará - UFPA no Norte, a Universidade Federal do Rio Grande do Norte - UFRN no Nordeste, a Universidade de Brasília - UnB no Centro-Oeste, a Universidade Federal do Rio de Janeiro - UFRJ no Sudeste e a Universidade Federal do Rio Grande do Sul - UFRGS no Sul. Esta seção apresenta os resultados encontrados a partir dos dados e informações levantadas sobre essas universidades, dividindose em duas subseções.

\subsection{AS UNIVERSIDADES ANALISADAS}

A instituição selecionada na Região Norte do Brasil é a Universidade Federal do Pará - UFPA, sediada no Estado do Pará, cuja sede instala-se na cidade de Belém. Foi criada pela Lei $\mathrm{n}^{\mathrm{o}}$ 3.191, de 1957, com 59 anos de história, expandindo-se para além da sede, em onze campi, nas cidades de Abaetetuba, Altamira, Ananindeua, Bragança, Breves, Cametá, Capanema, Castanhal, Salinópolis, Soure e Tucuruí, todos na região amazônica. (UFPA, 2015)

A missão institucional estabelece à UFPA "produzir, socializar e transformar o conhecimento na Amazônia para a formação de cidadãos capazes de promover a construção de uma sociedade sustentável", visionando "ser referência nacional e internacional como 
universidade multicampi integrada à sociedade e centro de excelência na produção acadêmica, científica, tecnológica e cultural." (UFPA, 2015, p. 29).

O setor da UFPA responsável pela área de Gestão de Pessoas, temática do presente artigo, é a Pró-Reitoria de Gestão e Desenvolvimento de Pessoal, que possui como competências (UFPA, 2015, p.32):

- Propor políticas e diretrizes de pessoal;

- Valorizar e desenvolver o servidor;

- Propor, coordenar, acompanhar e avaliar as políticas e diretrizes para recrutamento, seleção, capacitação, avaliação de desempenho, saúde e qualidade de vida dos servidores.

O Plano de Desenvolvimento Institucional 2011-2015 da UFPA (UFPA, 2011), vigente para o período em análise do artigo, dedica um capítulo exclusivo para a gestão de pessoas, cujo detalhamento está alinhado às competências da Pró-Reitoria responsável pela área, ao apontar a Política de Desenvolvimento e Valorização, a Política de Saúde e Qualidade de Vida, o Perfil do Corpo Docente, o Perfil do Corpo Técnico-Administrativo, indicando o regime de trabalho, o plano de carreira, os critérios de seleção e contratação e cronograma de expansão.

A Região Nordeste do Brasil possui a Universidade Federal do Rio Grande do Norte UFRN como selecionada, por apresentar o maior volume de recursos no orçamento de 2014 da região. Criada em 1958, com 58 anos de história, tem sua sede na cidade de Natal, Estado do Rio Grande do Norte, e outros quatro campi, localizados nas cidades de Macaíba, Santa Cruz, Caicó e Currais Novos. Inicialmente foi originada como uma instituição estadual, sendo federalizada em 1960. (UFRN, 2015).

A UFRN apresenta como missão institucional "Educar, produzir e disseminar o saber universal, preservar e difundir as artes e a cultura, e contribuir para o desenvolvimento humano, comprometendo-se com a justiça social, a sustentabilidade socioambiental, a democracia e a cidadania.” (UFRN, 2015, p. 14), sendo classificada como uma instituição de excelência nas regiões norte e nordeste brasileiro.

A Gestão de Pessoas na UFRN é de responsabilidade da Pró-Reitoria de Gestão de Pessoas, tendo como competências formular e implementar a política de gestão de pessoas da instituição, além de supervisionar e coordenar ações do PDI e do Plano de Gestão (UFRN, 2015). O Plano de Desenvolvimento Institucional da UFRN possui um horizonte de 2010- 
2019, apresentando dois capítulos para a área de gestão de pessoas, sendo o Corpo Docente e Corpo Técnico-Administrativo, em que apresenta a situação e a caracterização dessas categorias, sem, no entanto apontar ações propositivas para o futuro. Cabe destacar que a pesquisa documental indicou a existência do Plano de Gestão, documento este que provavelmente indica as ações para área de forma detalhada (UFRN, 2010).

A Universidade de Brasília - UnB é a instituição do Centro-Oeste brasileiro que possui o maior orçamento dentre as universidades federais da região, sendo uma das pesquisadas no artigo. Sua denominação e registro formal, como nas leis orçamentárias, é Fundação Universidade de Brasília - FUB, instituída em dezembro de 1961 pela Lei no 3.998, com 55 anos de existência, foi inaugurada em abril de 1962. Sediada no Distrito Federal, a expansão da instituição por campi ocorreu em cidades satélites, criando-se as Faculdades de Planaltina, Gama e Ceilândia (UNB, 2015).

A UnB iniciou em 2014 os trabalhos para a elaboração de seu Planejamento Estratégico 2014-2017, que definiu a missão em "ser uma instituição inovadora, comprometida com a excelência acadêmica, científica e tecnológica formando cidadãos conscientes do seu papel transformador na sociedade, respeitadas a ética e a valorização de identidades e culturas com responsabilidade social.", visionando "estar entre as melhores universidades do Brasil, inserida internacionalmente, com excelência em gestão de processos que fortaleça o ensino, pesquisa e extensão.” (UNB, 2015, p. 53).

O que comumente é denominado de pró-reitorias, na UnB tem a denominação de decanato, sendo o Decanato de Gestão de Pessoas responsável pelo tratamento dos colaboradores da instituição. Na estrutura institucional existe também a Câmara de Gestão de Pessoas, com a atribuição de fornecer pareceres, analisar propostas e projetos e regulamentar normas pertinente a sua área de atuação. Dentre os objetivos que a UnB delineou para a gestão de pessoas estão (UNB, 2015, p. 55):

- Capacitação e desenvolvimento dos servidores em gestão universitária;

- Valorização do desempenho profissional;

- Dimensionamento do quadro de pessoal conforme demanda da instituição;

- Implantação de políticas de retenção de talentos.

O PDI da UnB possui um capítulo específico no que tange a gestão de pessoas, denominado de Organização e Gestão de Pessoal, subdividindo-o em corpo docente e corpo técnico-administrativo, que além de estabelecer projeções de expansão do quadro, delineia 
metas e perspectivas para o ciclo de 2014 a 2017, no que tange a estrutura e atividades do Decanato e Câmara de Gestão de Pessoas (UNB, 2014).

Na Região Sudeste está a sede da Universidade Federal do Rio de Janeiro - UFRJ, que possui o maior orçamento dentre todas as universidades federais brasileiras. Com sede na capital do Estado do Rio de Janeiro, a UFRJ expandiu-se com o Campus de Macaé e o Campus de Xerém. Sendo a mais antiga das instituições, foi criada pelo Decreto $\mathrm{n}^{\circ} 14.343$, de setembro de 1920, sob o nome de Universidade do Rio de Janeiro, possuindo 96 anos de existência. Sua denominação atual ocorreu com a Lei ${ }^{0}$ 4.831, de novembro de 1965, tendo sido nominada a partir de 1937 como Universidade do Brasil (UFRJ, 2015).

O setor de gestão de pessoas na UFRJ é a Pró-Reitoria de Pessoal, que tem como responsabilidades a “[...] implantação, planejamento, monitoramento e alteração das políticas e gestão de pessoal da universidade.” (UFRJ, 2015, p. 537). Essa Pró-Reitoria atua em processos de dimensionamento e alocação, seleção e admissão, formação profissional, acompanhamento funcional, análise de capacitação, perícia em saúde, saúde e segurança do trabalhador, educação e promoção em saúde, gerenciamento da folha de pagamento e cadastro.

Até o término da pesquisa, não foi localizado o Plano de Desenvolvimento Institucional da UFRJ vigente, impossibilitando tratar de seu planejamento formalizado como as demais instituições.

Os três estados do sul do Brasil têm em suas capitais as principais universidades federais brasileiras, localizando-se na cidade de Porto Alegre, estado do Rio Grande do Sul, a sede da instituição com maior volume de recursos orçamentários da região: a Universidade Federal do Rio Grande do Sul - UFRGS. Criada inicialmente por um decreto estadual, em novembro de 1934, pretendeu reunir faculdades isoladas existentes desde 1895, sendo conhecida à época como Universidade de Porto Alegre. (UFRGS, 2015)

Ainda sob jurisdição estadual, trocou a denominação para Universidade do Rio Grande do Sul - URGS, ao incorporar faculdades de outras cidades além da capital. Foi federalizada em dezembro de 1950 pela Lei $n^{\circ} 1.254$, quando passou a possuir a denominação atual. Considerando sua história inicial, a UFRGS possui então 82 anos de existência. (UFRGS, 2015)

Apresentada em seu Estatuto, a missão da "Universidade Federal do Rio Grande do Sul tem por finalidade precípua a educação superior e a produção de conhecimento filosófico, 
científico, artístico e tecnológico integradas no ensino, na pesquisa e na extensão." (UFRGS, 2015, p. 33). A finalidade preconizada é observada pelos colaboradores que atuam na sede da instituição, na capital Porto Alegre, mas com perspectiva de consolidação da expansão das ações da instituição no campus Litoral Norte, município de Tramandaí, e no campus Serra, em município de mesmo nome.

A estrutura funcional da UFRGS é hierarquizada, tendo a Pró-Reitoria de Gestão de Pessoas - PROGESP, como área institucional responsável por planejar, executar e avaliar ações para a gestão dos docentes e técnico-administrativos. Ao descrever as competências do órgão, o redator frisou que a responsabilidade pela construção de uma instituição é de todos os servidores, e que a gestão destes demanda atenção de todos os demais órgãos da UFRGS. (UFRGS, 2015).

Além da PROGESP, a UFRGS possui duas comissões que contribuem para a área da gestão de pessoas, sendo a Comissão Permanente de Pessoal Docente - CPPD e a Comissão Interna de Supervisão - CIS. A primeira restringe-se à categoria docente, e a segunda trata dos técnico-administrativos, cada qual com suas especificidades de atuação. (UFRGS, 2015).

Até o término da pesquisa, não foi localizado o Plano de Desenvolvimento Institucional da UFRGS vigente, impossibilitando tratar de seu planejamento formalizado como as demais instituições.

\subsection{RELAÇÃO ENTRE QUANTITATIVO DE SERVIDORES, DISCENTES E ORÇAMENTOS}

A Tabela 1 apresenta os orçamentos totais e com pessoal identificados na Lei Orçamentária Anual.

Tabela 1 Orçamentos Total e de Pessoal de Universidade Federais, por Região Brasileira.

\begin{tabular}{ccccc}
\hline Universidade & Região & $\begin{array}{c}\text { Orçamento 2014 R\$ } \\
(\mathbf{a})\end{array}$ & $\begin{array}{c}\text { Orçamento de Pessoal } \\
\text { R\$ (b) }\end{array}$ & \%b/a \\
\hline UFRJ & Sudeste & $\mathrm{R} \$ 2.358 .770 .807$ & $\mathrm{R} \$ 1.856 .376 .825$ & 78,70 \\
UnB & Centro-Oeste & $\mathrm{R} \$ 1.575 .450 .885$ & $\mathrm{R} \$ 954.148 .045$ & 60,56 \\
UFRGS & Sul & $\mathrm{R} \$ 1.381 .441 .759$ & $\mathrm{R} \$ 1.088 .268 .892$ & 78,78 \\
UFRN & Nordeste & $\mathrm{R} \$ 1.170 .422 .609$ & $\mathrm{R} \$ 880.143 .084$ & 75,20 \\
UFPA & Norte & $\mathrm{R} \$ 1.011 .481 .527$ & $\mathrm{R} \$ 716.586 .327$ & 70,85 \\
\hline
\end{tabular}

Fonte: LOA 2015.

Os dados da tabela 1 demonstram que o orçamento da UFRJ, região Sudeste, é o que apresenta maior volume de recursos, ultrapassando 2,3 bilhões de reais, enquanto que o menor 
orçamento é da UFPA, região Norte, com 1 bilhão de reais aproximadamente. O orçamento da UFRJ é mais que o dobro dos orçamentos da UFPA e UFRN individualmente.

O orçamento de pessoal considerou o que a Lei Orçamentária Anual de 2015 enquadra como Grupo de Despesa o item Pessoal e Encargos Sociais, incluso além da remuneração e encargos dos docentes e técnico-administrativos na ativa, também a previdência de inativos e pensionistas. A análise da tabela 1 indica que o orçamento de pessoal na UFRJ é o que possui maior volume de recursos entre as instituições estudas, enquanto que a UFPA possui o menor orçamento.

O volume de recursos orçamentários de pessoal aparenta acompanhar com alguma proporção o orçamento total das instituições, pois de acordo com a tabela 1, o percentual do primeiro sobre o segundo é aproximadamente $75 \%$. Esse percentual indica que, do orçamento total das instituições, os gestores possuem apenas $25 \%$ disponíveis para despesas correntes e investimentos, ou no caso mais expressivo, da UFRJ, apenas 21\%. Deduzindo as despesas fixas, como energia elétrica, telefonia, água, limpeza e outros, o saldo restante para utilizações discricionárias do gestor é muito baixo, o que demanda dos mesmos recorrerem por negociações com autoridades em Brasília e busca por recursos próprios.

Essa constatação não é observada na UnB, cujo percentual do orçamento de pessoal compromete $60,56 \%$ do orçamento total da instituição, conforme a tabela 1 , o que possibilita a utilização de quase $40 \%$ do restante do orçamento com outras despesas.

A ilustração 1 apresenta os dados orçamentários dispostos em formato de gráfico de colunas, possibilitando um comparativo visual entre as cinco instituições, bem como a linearidade de seus orçamentos totais.

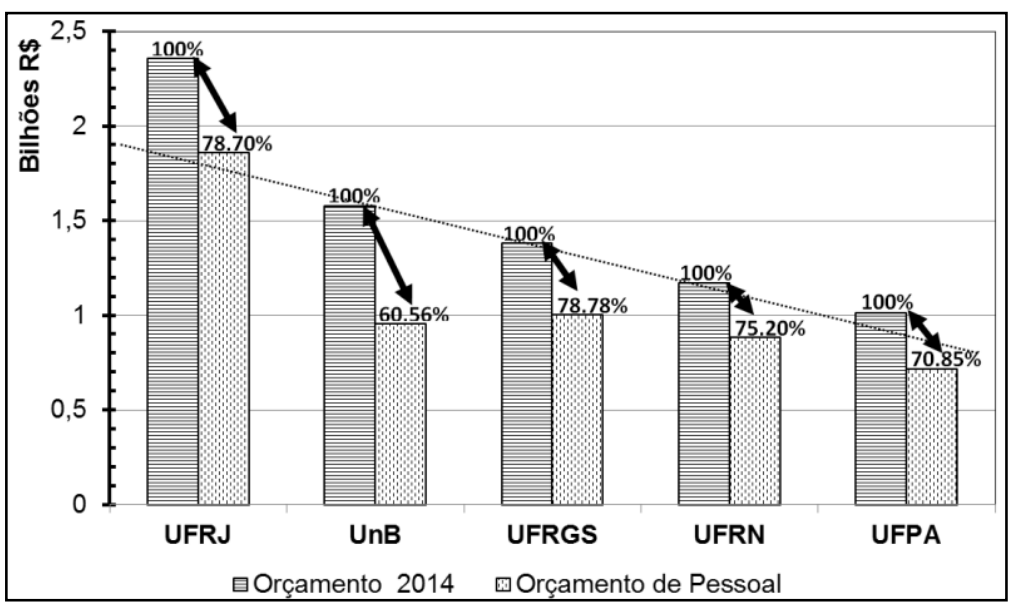

Ilustração 1. Dados orçamentários de 2014 da UFRJ, UnB, UFRGS, UFRN e UFPA. Fonte: LOA, 2015. 


\section{ANÁLISE COMPARATIVA DE CINCO UNIVERSIDADES FEDERAIS BRASILEIRAS: RELAÇÕES ENTRE ORÇAMENTOS, SERVIDORES E DISCENTES \\ DOI: http://dx.doi.org/10.5007/1983-4535.2016v9n3p67}

Observa-se pela ilustração 1 que a reta traçada, quando analisada da direita para a esquerda, possui um crescimento linear dos orçamentos totais de 2014 entre quatro instituições (UFPA, UFRN, UFRGS e UnB), o que não se observa com a UFRJ, cujo comportamento orçamentário acarreta uma discrepância da reta de forma positiva, fugindo da constância das outras quatro instituições.

O orçamento de pessoal possui similaridades de proporção ao orçamento total, mas como apresentado na ilustração 1, a UnB é a única instituição cujo percentual foge do padrão observado nas outras quatro instituições.

A tabela 2 apresenta o quantitativo de servidores docentes e técnico-administrativos das universidades federais objeto de estudo da pesquisa, cujas remunerações e encargos são considerados no orçamento de pessoal apresentado na tabela 1.

Tabela 2 Quantitativo de servidores da UFRJ, UnB, UFRGS, UFRN e UFPA, ano de 2014.

\begin{tabular}{cccc}
\hline Universidade & Docentes & Técnico-Administrativos & Orçamento de Pessoal R\$ \\
\hline UFRJ & 5.705 & 9.566 & $\mathrm{R} \$ 1.856 .376 .825$ \\
UnB & 2.397 & 2.770 & $\mathrm{R} \$ 954.148 .045$ \\
UFRGS & 2.770 & 2.746 & $\mathrm{R} \$ 1.088 .268 .892$ \\
UFRN & 2.689 & 3.273 & $\mathrm{R} \$ 880.143 .084$ \\
UFPA & 2.131 & 2.323 & $\mathrm{R} \$ 716.586 .327$ \\
\hline
\end{tabular}

Fonte: LOA (2015) e Relatórios de Gestão Institucionais (2015).

Observa-se pelos dados apresentados na tabela 2 que o quantitativo de técnicoadministrativos geralmente é maior que o quantitativo de docentes, podendo ser o indício de que o suporte às atividades docentes demanda uma força de trabalho maior que a própria atividade fim das instituições. A exceção está apenas com a UFRGS, cuja relação entre técnicos e docentes é próximo a 1.

A tabela 2 também evidencia que o quantitativo de docentes e técnicos, em geral, concentra-se entre 2.131 a 3.273 colaboradores em cada categoria, com um intervalo de 1.142 entre as instituições. A exceção fica com a UFRJ, cuja quantidade de docentes aproxima-se do dobro da próxima colocada, a UFRGS, e de técnicos aproxima-se do triplo da próxima colocada, a UFRN.

Ao realizar a comparação entre o quantitativo de colaboradores com os orçamentos de pessoal, observa-se a UnB distante do padrão, pois apesar de possuir menor quantitativo de docentes e técnico-administrativos em relação a UFRGS e UFRN, seu orçamento de pessoal é maior ou próximo destas. 
A tabela 3 a seguir acrescenta o quantitativo de alunos de cada instituição, e aponta a relação, em número inteiros, entre quantidades de alunos por docentes e técnicoadministrativos.

Tabela 3 Relação, em números inteiros, entre quantitativo de alunos com servidores da UFRJ, UnB, UFRGS, UFRN e UFPA, ano de 2014.

\begin{tabular}{cccccc}
\hline Universidade & $\begin{array}{c}\text { Docentes } \\
(\mathbf{a})\end{array}$ & $\begin{array}{c}\text { Técnico-Administrativos } \\
(\mathbf{b})\end{array}$ & $\begin{array}{c}\text { Alunos } \\
(\mathbf{c})\end{array}$ & $\mathbf{c} / \mathbf{a}$ & c/b \\
\hline UFRJ & 5.705 & 9.566 & 43.417 & 7 & 4 \\
UnB & 2.397 & 2.770 & 29.837 & 12 & 10 \\
UFRGS & 2.770 & 2.746 & 26.311 & 9 & 9 \\
UFRN & 2.689 & 3.273 & 28.495 & 10 & 8 \\
UFPA & 2.131 & 2.323 & 27.097 & 12 & 11 \\
\hline
\end{tabular}

Fonte: Relatórios de Gestão Institucionais (2015).

O quantitativo de alunos evidenciado na tabela 3 demonstram que a UFRJ possui aproximadamente quinze mil alunos a mais que a média das demais instituições, sendo um indicativo das razões por possuir maior quantitativo de servidores e de orçamento, como apresentados nas tabelas 1 e 2. Enquanto a média aproximada é de vinte e sete mil alunos de graduação, a UFRJ possui próximo de quarenta e três mil.

Observa-se também que a relação de alunos por docentes e técnicos na UFRJ é a menor entre as instituições, com sete alunos para cada docente e quatro alunos para cada técnico. A UFPA é a instituição que possui a maior relação, sendo doze alunos por docentes e onze alunos por técnico-administrativo.

Apesar de haver um indicativo de padrões, de forma isolada e com exceções, nas quantidades de docentes, técnicos e alunos, não foi possível constatar o mesmo padrão na interrelação entre quantidade de alunos com docentes e técnicos. Entretanto, é observável algum padrão na quantidade de alunos com os orçamentos totais das instituições, quando esses dados nas tabelas 1 e 3 são comparados.

\section{CONCLUSÕES}

Tendo por objetivo analisar a possível relação entre quantitativo de servidores, discentes e orçamentos das universidades federais brasileiras, a metodologia de escolha dos casos selecionou uma universidade por região brasileira, cujo critério adotado foi o orçamento total. Assim, os resultados apresentaram a UFPA da Região Norte, a UFRN da Região Nordeste, a UnB da Região Centro-Oeste, a UFRJ da Região Sudeste, e a UFRGS da Região Sul. 
De acordo com os resultados apresentados, o ano de criação das instituições foram 1957, 1958, 1961, 1920 e 1950 respectivamente. É possível concluir que houve um período da história cuja política nacional era favorável às federalizações das universidades, que compreendeu, pelos casos estudados, as décadas de 50 e 60 . Apesar desse período de federalização, a existência da infraestrutura física era mais antiga, e geralmente, reunia várias faculdades isoladas existentes. A UFRJ é a mais antiga dentre as instituições estudadas, sendo também a que possui maior quantitativo de orçamento, servidores e estudantes, possibilitando concluir que, quanto mais antiga for a instituição, maior será o acúmulo incremental de pessoal (servidores e discentes), e consequentemente, de orçamento para absorver a estrutura necessária.

Os casos apresentados possibilitam concluir também que todas as universidades federais estudadas possuem um órgão no staff superior responsável pela gestão de pessoas, denominada de pró-reitoria, ou no caso da UnB, de decanato. A UnB possui também um órgão colegiado para a área, denominada de Câmara de Gestão de Pessoas, não observado nas demais instituições. Resgatando os aspectos teóricos apresentados, as universidades adotam as práticas contemporâneas para a gestão de pessoas, não apenas por ter um órgão especializado no assunto, mas também pelo fato de, em seus Relatórios de Gestão e PDI's apontarem que praticam ações que se enquadram no novo papel da área de recursos humanos.

É possível afirmar que as instituições estudadas que possuem PDI vigente preocupamse em dedicar uma seção para a gestão de pessoas, abordando políticas para as categorias de docentes e técnico-administrativos. Esse tratamento pode ser em decorrência das dimensões/eixos dispostas na legislação do SINAES. Curiosamente, apesar de obrigatório por força de legislação federal, a UFRJ e a UFRGS não possuíam PDI vigente até o fechamento da presente pesquisa.

Referente aos orçamentos totais e de pessoal apresentados nos resultados, é possível concluir que, das universidades federais estudadas, o orçamento de pessoal compõe a maior parte do orçamento total das instituições, deixando pouca margem para outros itens do orçamento. Conclui-se neste estudo que há coerência nesse dispêndio, em virtude das atividades fins das instituições somente se concretizarem com pessoal de alto nível, diferentemente de indústrias, por exemplo, cujas atividades fins dependem muito de recursos materiais e físicos. Portanto, é natural que a organização universidade, cujo conhecimento é o 
recurso de maior importância, tenha os seus colaboradores como atores principais do processo, o que reflete nos orçamentos.

Respondendo ao objetivo do artigo, é possível concluir que não há relação direta e inter-relacionamento entre quantitativo de servidores, discentes e orçamentos das universidades federais brasileiras, pois uma das instituições apresenta dados claramente fora do padrão. Apenas duas variáveis possuem relação quando analisadas de forma isolada, mas com uma instituição fora do padrão. Nesse caso foi possível relacionar somente o quantitativo de estudantes e orçamento das instituições de modo geral.

Seria interessante, para pesquisas futuras, buscar compreender as razões de não haver inter-relacionamento entre quantitativo de servidores, discentes e orçamentos das universidades federais brasileiras, identificando quais as lógicas existentes para se explicar o quadro apresentado.

\section{REFERÊNCIAS}

AQUINO, Cléber Pinheiro de. Administração de recursos humanos: uma introdução. Brasil: Atlas, 1980.

ARAUJO, Luis Cesar G. de: GARCIA, Adriana Amadeu. Gestão de pessoas: estratégias e integração organizacional. Brasil: Editora Atlas, 2009.

BRASIL. Instruções para elaboração de Plano de Desenvolvimento Institucional. Sistema de Acompanhamento de processos das Instituições de Ensino Superior. Ministério da Educação, Atualizado em 05/06/2007. 2007. Disponível em < http://www2.mec.gov.br/sapiens/pdi.html>.

BRASIL. Lei n ${ }^{\circ} 10.861$, de 14 de abril de 2004. Institui o Sistema Nacional de Avaliação da Educação Superior - SINAES e dá outras providências. Diário Oficial da União, Poder Executivo, Brasília, DF, nº 72, 15 abr. 2004a. Seção 1, p. 03.

BRASIL. Plano de Desenvolvimento Institucional - PDI Diretrizes para Elaboração. Ministério da Educação. Secretaria da Educação Profissional e Tecnológica. Sistema de Acompanhamento de Processos das Instituições de Ensino Superior - SAPIENS/MEC, $2004 b$.

BRASIL. Portaria n. ${ }^{\circ}$ 637, de 13 de maio de 1997. Dispõe sobre o credenciamento de universidades. Ministério da Educação. Disponível em <

http://portal.mec.gov.br/sesu/arquivos/pdf/p637.pdf >

CNE, Conselho Nacional de Educação. Resolução nº 10 , de 11 de março de 2002. 
CRUZ, Carla; RIBEIRO, Uirá. Metodologia científica: teoria e prática. Rio de Janeiro: Axcel Books, 2003.

DUTRA, Joel S. A utopia da mudança das relações de poder na gestão de recursos humanos. In: FLEURY, M. T. L.; FISCHER, R. M. (coord.). Cultura e poder nas organizações. 2. Ed. Brasil: Atlas, 1996.

DUTRA, Joel S. Gestão de pessoas: modelos, processos, tendências e perspectivas. São Paulo: Atlas, 2002.

FLIPPO, Edwin B. Princípios de administração de pessoal. $2^{\mathrm{a}}$ Ed. Brasil: Atlas, 1978. (v.1).

FRANCISCO, Thiago Henrique Almino et al. A contribuição do PDI nas atividades de planejamento e gestão das instituições de educação superior. Revista Gestão Universitária na América Latina - GUAL, v. 5, n. 3, p.81-107, 21 dez. 2012. Universidade Federal de Santa Catarina (UFSC).

FRANZONI, A. M. B.; LAPOLLI, E. M. (coord.). Gestão de pessoas em organizações empreendedoras. Brasil: Pandion, 2009.

GIL, Antonio Carlos. Como elaborar projetos de pesquisa. 5. ed. São Paulo: Atlas, 2010.

LOBOS, Júlio A. Administração de recursos humanos. Brasil: Editora Atlas, 1979.

MATTAR, João. Metodologia Científica na Era da Informática. 3. ed. São Paulo: Saraiva, 2008.

MAXIMIANO, Antonio Cesar Amaru. Introdução à administração. Edição 5. Brasil: Editora Atlas, 2000.

MAXIMIANO, Antonio César Amaru. Teoria geral da administração: da revolução urbana à revolução digital. Edição 6. Brasil: Editora Atlas, 2011.

MURIEL, Roberta. Plano de desenvolvimento institucional - PDI: análise do processo de implantação. Brasil: Editora Hoper, 2006.

OLIVEIRA, Djalma de Pinho Rebouças de. Planejamento estratégico: conceitos, metodologias e práticas. Edição 25. Brasil: Atlas, 2008.

RIBEIRO, Antonio de Lima. Gestão de Pessoas. Brasil: Editora Saraiva, 2006.

UFPA, Universidade Federal do Pará. Plano de Desenvolvimento Institucional 2011-2015. Belém: UFPA 2011. Disponível em:

$<\underline{\text { https://www.portal.ufpa.br/docs/pdi aprovado final.pdf }>}$

UFPA, Universidade Federal do Pará. Relatório de Gestão do Exercício de 2014. Belém: UFPA 2015. Disponível em:

https://contas.tcu.gov.br/egestao/ObterDocumentoSisdoc? codPapelTramitavel=52857024 
UFRGS, Universidade Federal do Rio Grande do Sul. Relatório de Gestão do Exercício de 2014. Porto Alegre: UFRGS 2015. Disponível em:

$<$ https://contas.tcu.gov.br/egestao/ObterDocumentoSisdoc?codPapelTramitavel=52816223 $>$

UFRJ, Universidade Federal do Rio de Janeiro. Relatório de Gestão do Exercício de 2014. Rio de Janeiro: UFRJ 2015. Disponível em:

$<$ https://contas.tcu.gov.br/egestao/ObterDocumentoSisdoc?codPapelTramitavel=53447926>

UFRN, Universidade Federal do Rio Grande do Norte. Plano de Desenvolvimento

Institucional 2010-2019. Natal: UFRN 2010. Disponível em:

$<$ https://sistemas.ufrn.br/shared/verArquivo?idArquivo=637863\&key=d52c937a619f6f6ecb4 $624 \mathrm{a} 62654 \mathrm{f} 857>$

UFRN, Universidade Federal do Rio Grande do Norte. Relatório de Gestão de Exercício de 2014. Natal: UFRN 2015. Disponível em:

$<$ https://contas.tcu.gov.br/egestao/ObterDocumentoSisdoc?codPapelTramitavel=52857339>

UNB, Universidade de Brasília. Plano de Desenvolvimento Institucional 2014-2017.

Brasília: UNB 2014. Disponível em: <http://www.dpo.unb.br/documentos/PDI/PDI_20142017.pdf>

UNB, Universidade de Brasília. Relatório de Gestão do Exercício de 2014. Brasília: UNB 2015. Disponível em:

$<$ https://contas.tcu.gov.br/egestao/ObterDocumentoSisdoc?codPapelTramitavel=53157875> 